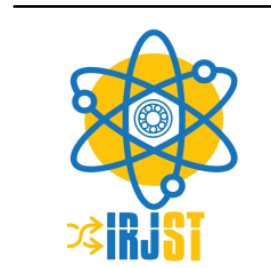

Available online at https://www.irjst.com/

International Research Journal of Science and Technology

ISSN:2707-3955

DOI: https://doi.org/10.46378/irjst.2019.010107

\title{
A Review on the Investigation of Biologically Active Natural Compounds on Cotton Fabrics as an Antibacterial Textile Finishing
}

\author{
Franco John Unango ${ }^{1,2 *} \&$ Karthikeyan M Ramasamy ${ }^{2}$ \\ ${ }^{1}$ Department of Chemistry, College of Education, University of Bahr el Ghazal, Wau, South Sudan. \\ ${ }^{2}$ Department of Chemistry, Arba Minch University, Arba Minch, Ethiopia.
}

Published: 2019

\begin{abstract}
The scientific studies have considered the propolis, beewax and Chitosan as antibacterial agents for $100 \%$ cotton fabrics in recent years as an emulsion to functionalize cotton textile materials. But yet no more research had done on these natural compounds. Chitosan has a long historical background of being used as an antibacterial agent in different fields. The concentration, Molecular Weight, and Degree of Deacylation of chitosan and the bacterial strain are the main factors that affect the antibacterial behavior of chitosan. The used of chitosan as an antibacterial finish along with a durable press finishing agent on $100 \%$ cotton fabrics was found that antibacterial activity remained to a level of $80 \%$ after 10 repeated launders. The presence of the biologically active natural compounds on the cotton substrates modified the surface of the textile fibers. The treatment also improved fabric comfort properties, the cotton substrates became less air permissive and more hygroscopic after the treatment. The research found that the treated cotton fabric showed higher reduction $(97 \%)$ in the number of colonies of $\mathrm{S}$. aureus bacteria compared to the number of colonies on a $55 / 45 \%$ wood pulp/polyester spun-laced nonwoven fabric.The antibacterial performance of the functionalized cotton fabrics treated with those biologically active natural compounds has the potentials to be used in medical fields[1]. Furthermore, the used of microcapsules of honey as core and chitosan as a shield on the medical gauzes showed good performance in the wound healing. These treated medical gauzes have the healing and antimicrobial behaviors of honey and chitozan and that study had proved the usage of honey and Chitosan as an antibacterial in treating medical gauzes for the human diabetes [2]. Up to date none of the natural compounds have been reported to have negative side effects on the human skin when used as antibacterial clothing.
\end{abstract}

Key Words

Bamboo

Cotton

Beewax

Propolis

Chitosan

Natural compound

Antibacterial

Copyright (2019: Franco John Unango and Karthikeyan M Ramasamy. This is an open access distribution, and reproduction in any medium, provided Access article distributed under the Creative Commons Attribution License the original work is properly cited License, which permits unrestricted use.

Citation: Franco John Unango and Karthikeyan M Ramasamy."A review on the investigation of biologically active natural compounds on cotton fabrics as an antibacterial textile finishing", International Research Journal of Science and Technology, 1(1), 49-55, 2019

\section{Introduction}

Cotton materials have unique medical and healthcare applications because of their rewards such as biodegradability, softness, affinity to skin and sweat absorption [1].

\footnotetext{
${ }^{*}$ Corresponding author: Franco John Unango

Department of Chemistry, College of Education,

University of Bahr el Ghazal, Wau, South Sudan

Email: majigoifranco@gmail.com
}

Oppositely, Cotton fabrics also provide conducive environment for growth of microbial(bacteria, fungi, algae, virus, Mould, mildew, yeast, etc) due to their large surface area and ability to retain moisture [2]. The growth of microorganisms on textiles inflicts a range of unwanted effects not only on the textile itself but also on the wearer under favorable conditions like moisture, Temperature, dirt, receptive surface, perspiration, food articles and warmth. The effects 
include the generation of unpleasant odor, stains and discoloration in the fabric, a reduction in fabric mechanical strength and an increased likelihood of contamination[3].

Many different compounds are being used to impart antibacterial functionality to textiles, ranging from synthetic compounds such as cationizing agents (quaternary ammonium salts), triclosan, metals and metal salts (Silver, Zinc, Copper), oxidizing agents (halogens, aldehydes, and peroxy compounds), amines (biguanides and glucoprotamine), antimicrobial dyes to naturally derived antimicrobials, such as chitosan, and essential oils (Lavander, Rosemary, Pomegranate, Aloe Vera, Prickly Chaff Flower, Turmeric, Clove etc.). Changes in consumers' preferences toward natural products rather than synthetic stimulate the use of natural products in textile industry [4]. The word "propolis" is derived from the Greek words, pro "in front of or at the entrance to" and polis "community or city" and it means a substance in defense of the hive. Propolis, or bee glue, is a brownish resinous material collected by worker bees from the leaf buds of numerous tree species like birch, poplar, pine, alder, willow, palm, Baccharisdracunculifolia, and Dalbergiaecastaphyllum [5, 6].

Propolis is a natural product which is a mixture of resin and beeswax of numerous tree species collected from vital parts of plants, particularly from flowers and leaf buds by honey bees (Apismelliferaand Trigona species (stingless bee)). Bees used propolis as defense substance against infections and parasites and to seal off the beehive openings in order to avoid air, killed insects, bacteria and moulds entering the hives. Modern science has confirmed the antimicrobial and antiviral action of propolis, and has discovered numerous other beneficial. Over 180 propolis components have been identified, including flavanoids compounds which are responsible for antibacterial activity of propolis. propolis is known for its antibacterial, antifungal, antivirulant, antiinflammatory, hepatic protective, antioxidant and allergenic properties. The components of propolis vary depending on the season, geographical location and on the source from which the resinous exudates have been collected [7, 8].

Beewax is the substance that forms the structure of a honeycomb and is a complex product secreted in liquid form by special wax glands in the abdomen of younger workers (aged 12-18 days) and it solidifies in scalesin contact with the air [9].

Beeswax is water repellent, presents specific emulsion properties, creates good lubrication and improves the touch of textile fabrics. Beeswax is similar to propolis, made up of different components based on the sources collected from and their geographical regions, and consists mainly of esters of higher fatty acids. The few studies showed the antimicrobial effectiveness of beeswax against overall Staphylococcus aureus, Salmonella enterica, Candida albicans and Aspergillusniger; these inhibitory effects are enhanced synergistically with other natural products such as honey and olive oil [10].

Chitosan is an abundant biopolymer, consisting of poly [ $\beta$-(1-4)-2-amio-2-deoxy-D-glucopyranose] which is obtained after alkaline deacetylation of the chitin which is found in exoskeletons of crustaceans, arthropods and mollusks, as well as the cell walls of certain fungi [11].

Chitin and chitosan are polysaccharides, chemically similar to cellulose differing only by the presence or absence of nitrogen. Chitosan is a low acetyl form of chitin mainly composed of glucosamine, 2-amino-2deoxy-b-D-glucose.

The positive charge of chitosan confers to this polymer numerous and unique physiological and biological properties such as antibacterial and Immuno-enhancing characteristics, non-toxicity, and biodegradability with great potential in a wide range of industries [12]. In addition, chitosan induces a series of defence reactions correlated with enzymatic activities. The concentration, molecular weight (MW), and degree of deacetylation (DD) of chitosan and the bacterial strain are the main factors that affect the antibacterial behavior of chitosan.

\subsection{The Need for Antibacterial Finish in Textiles}

Microbes are the tiniest creatures that cannot be seen by naked eyes. They include a variety of microorganisms like bacteria, fungi, algae and virus.Some specific types of bacteria are pathogenic and cause cross infection. Fungi, moulds or mildew are complex organisms with slow growth rate. They stain the fabric and deteriorate its performance properties. Cotton textiles in contact with the human body offer an ideal environment for microbial growth.

To protect the textiles and mankind from pathogen and to avoid cross infection; a special finish like antibacterial finish has become necessary. The purpose of imparting antibacterial activity to textiles is to protect the material from microbial attack, prevent the transmission and spreading of pathogenic microorganisms, inhibit odour development resulting from microbial degradation, and creating a material that will act as preventive/curative treatment [13]. 


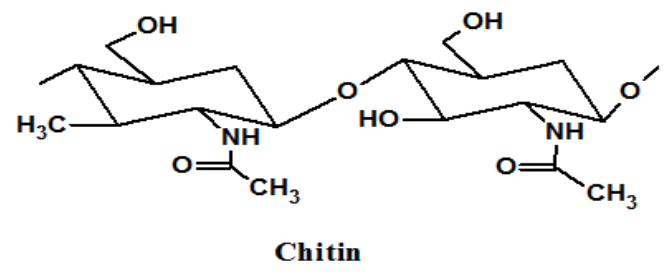

[B(1,4)-acetam id o-2-d eoxy-D-glycopyranose]

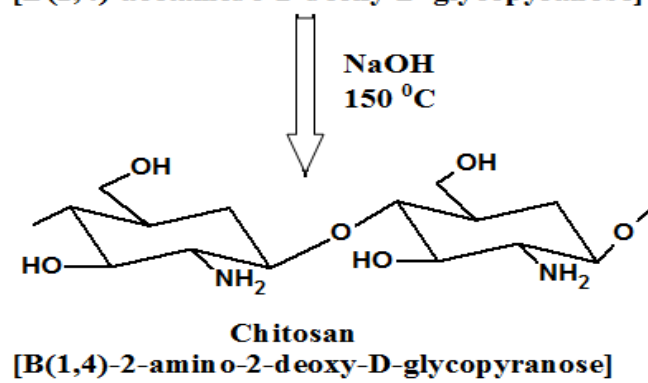

Figure 1: Deacetylation of chitin to chitosan [14].
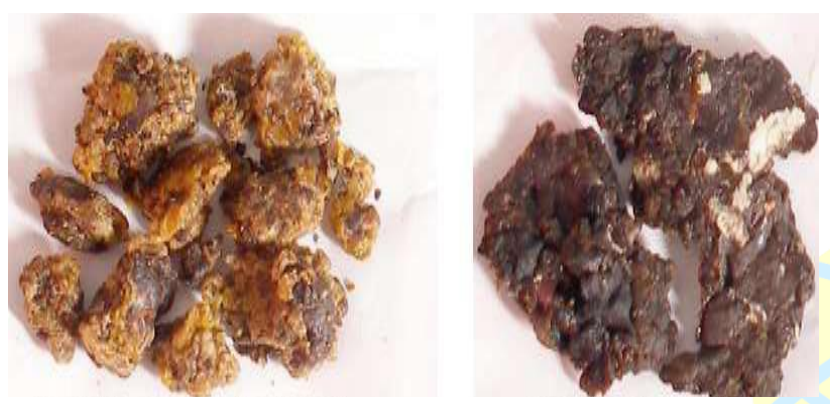

Figure 2 .Propolis samples of Apismelifera and Trigona species [15]

\subsection{Conditions Necessary for Antibacterial in Textile Industry}

Antibacterial treatment for textile materials is necessary when fulfill the following conditions: Avoid cross infection by pathogenic microorganisms, Control the infestation by microbes, Arrest metabolism in microbes in order to reduce the formation of: odour, Safeguard the textile products from staining, discoloration and quality deterioration. Safety to the consumer by using low toxicity products, not causing allergies or irritation to the skin, not causing any negative impact on textile properties or appearance, being compatible with textile processing methods, Providing durability to laundering processes and economically effectiveness [16].

\subsection{Types of Antibacterial Agents}

There are several different classifications for antimicrobial agents based on the chemistry, the mechanism of antimicrobial activity, efficiency, and washing resistance and are grouped into three basic chemical compositions: organo-phenols, organosilanes, and organometallics. Antimicrobial substances can be divided into biocides and biostats, leaching and bound antimicrobials, controlled-release and barrier-forming agents, synthetic and natural, and agents of poor and of good washing resistance [17].

\subsection{Emulsion Development of Biological Natural Compounds}

The emulsions were obtained by the mixing under agitation at $80{ }^{\circ} \mathrm{C}$ : beeswax, chitosan, Ethanol Extract of Propolis (EEP), glycerol, non-ionic surfactant Tween 80 , and water. In order to identify the influence of each of the main ingredients, a number of seven emulsion variants were prepared, and beeswax, EEP, and chitosan varying in concentrations (Table 1). The $\mathrm{pH}$ of the emulsion was set to be 4-6. The fabrics were impregnated with the emulsion at $50{ }^{\circ} \mathrm{C}$, using a Benz padding machine adjusted to a wet pickup of $150 \%$ [1].

Table1. The formulations of the emulsions used for the treatment

\begin{tabular}{|c|c|c|c|c|c|c|c|}
\hline Compound & 1 & 2 & 3 & 4 & 5 & 6 & 7 \\
\hline Beewax & 12.5 & 25 & 37.5 & 25 & 25 & 25 & 25 \\
\hline Glycerol & 100 & 100 & 100 & 100 & 100 & 100 & 100 \\
\hline Tween 80 & 30 & 30 & 30 & 30 & 30 & 30 & 30 \\
\hline Chitosan 1\% (m/v) $\mathrm{ml} / \mathrm{l}$ & 200 & 200 & 200 & 100 & 300 & 200 & 200 \\
\hline EEP 30\% $(\mathrm{m} / \mathrm{v}) \quad \mathrm{ml} / \mathrm{l}$ & 75 & 75 & 75 & 75 & 75 & 25 & 125 \\
\hline
\end{tabular}

\subsection{Methods of Application of Antibacterial onto} the Fabrics

Several processes are being used to apply antibacterial finishes to fabrics:

The conventional technologies: These include;

Exhaustion, padding, low add-on processes, foam application, printing, and coating. The pad-dry-cure process:the antimicrobial solutions are applied to the fabric in a bath through rollers under pressure to pressed chemicals into the fabrics. Then, dried in an oven and finally cured in the oven at a higher temperature to ensure bonding.

Modern technologies: Employed for the antibacterial agents that are used in either industry or academia having the following mechanisms:

Controlled-release mechanism:The most commonly used antibacterial. The agent is released gradually in enough quantities to kill or inhibit the growth of bacteria. eg. gentamincin and triclosan.

Regeneration mechanism: Whereby an antibacterial chemical finish is applied to the fabric and is continually replenished by bleaching agents during laundering. eg. Monomethylol-5,5-dimethylhydantoin (MDMH).

Barrier-block mechanism: It inhibits bacteria through direct surface contact. The antibacterial agent can bond covalently to the fabric to form a strong and durable 
bond. Agent with the barrier-block mechanism do not leach and have fewer problems in skin irritation hence, required less antibacterial agents on fabrics [18].

\subsection{Antimicrobial Testing}

Anti-microbial testing was done as per AATCC test method 100:2004 for the quantitative assessment of the antibacterial effectiveness against Gram positive bacteria (Staphylococcus aureus) and Gram negative bacteria (Escherichia coli). Circular swatches of $4.8 \pm$ $0.1 \mathrm{~cm}$ in diameter were cut from the test fabric, stacked in $250 \mathrm{ml}$ wide mouth glass jar with a screw cap followed by sterilization at $121^{\circ} \mathrm{C}$ for $15 \mathrm{~min} .0 .5$ $\mathrm{ml}$ of the bacterial solution was added to the swatches to be absorbed by one swatch. The jar was kept for 24 $\mathrm{h}$ in the incubator at $37{ }^{\circ} \mathrm{C}$. Then $50 \mathrm{ml}$ of sterilized saline water was added to each jar followed by $15 \mathrm{~min}$ shaking in the shaker. Three sequential dilutions were done by taking $100 \mu \mathrm{l}$ in $900 \mu \mathrm{l}$ of saline water in eppendorf micro test tubes. Nutrient agar plates were made and $100 \mu \mathrm{l}$ of this diluted bacterial solution was introduced into the agar plate and incubate for $24 \mathrm{~h}$ at $37{ }^{\circ} \mathrm{C}$. The following day, the number of bacterial colony forming unit (CFU) on the agar plate were counted with untreated cotton sample as control group. Percentage reduction (R \%) of bacterial growth was calculated in comparison with untreated fabric according to following relationship [19] :

$$
\mathrm{R}(\%)=\left(\frac{\mathrm{U}-\mathrm{T}}{\mathrm{U}}\right) \times 100
$$

Where, $\mathbf{R}(\boldsymbol{\%})=$ Percentage reduction of bacterial growth. $\mathbf{U}=$ the number of bacteria $\mathrm{CFU}$ recovered from the inoculated untreated cotton test specimen swatches. $\mathbf{T}=$ the number of bacteria $\mathrm{CFU}$ recovered from the inoculated treated test specimen swatches.

\section{Evaluation of Treated Cotton Fabrics in Various Methods}

\subsection{Evaluation of Antibacterial Activity before and after Padding Methods}

By using AATCC test method 100:2004, antimicrobial activity for both untreated and treated cottons were evaluated for antimicrobial activity against Gram positive and Gram negative bacteria before and after each laundering cycle up to five times by using $5 \mathrm{~g} / \mathrm{L}$ laundry soap solution with $2 \mathrm{~g} / \mathrm{L} \mathrm{Na}_{2} \mathrm{CO}_{3}$, bath ratio of $1: 50$ at $35-37{ }^{\circ} \mathrm{C}$ in laundero-meter. Physical properties of finished fabrics were evaluated for total wrinkle recovery (TCRA, AATCC Test 66-2003), tensile strength (ISO 13934-1:1999), tearing strength (ASTM D1424-09), bending length (ASTM D1388), air permeability (AP, BS 5636) and whiteness index using spectrophotometer (Datacolor Check, USA) was used at $400 \mathrm{~nm}$ wavelength [20].

\subsection{Evaluation of Antibacterial Activity in Wet Conditions}

Antibacterial cotton fabric was prepared by graft copolymerization of acrylic acid (AA) and itaconic acid (IA) onto a cotton fabric in an aqueous medium. Ammonium per sulfate (APS) was utilized as an initiator in the presence of methylene bisacrylamide (MBA). The nano composite hydrogel was obtained from in situ formation of silver nanoparticles from reduction of silver cations by sodium borohydride. A planned mechanism for nanocomposite development was proposed and the effect of ratio of IA to AA on water absorbency was observed. Cotton fabric was inserted with a poly (acrylic acid-coitaconic acid) via ammonium per sulfate induced graft co-polymerization in an aqueous medium.

Then the fabric loaded with Ag nano particles by trap of $\mathrm{Ag}+$ ions into a grafted polymer network followed by borohydride reduction. The resultant dark brown color of the grafted fabric indicated the formation of $\mathrm{Ag}$ nano particles. This preparation of $\mathrm{Ag}$-coated fabric can be used as protective clothing (surgical masks, caps, gowns, etc.), hospital linen and clinical applications.

The equilibrium water absorbency of various samples increased as the mol ratio of IA to AA increased up to 0.08 . The incorporation of IA into higher IA content would lead to an increase in electrostatic repulsive force between charge sites on carboxylate ions upon their dissociation and cause a higher swelling ratio of the hydrogels in tap water. But with higher increase in the ratio of IA in monomer composition, the water absorbency decreased because the presence of IA in the monomer mixture made the hydrogel formation more difficult [21].

\subsection{Evaluation of Comfort Characteristics}

When considering wound, dressings and bandages, comfort properties are very important in defining the patient's wellbeing. The comfort characteristics of the knitted substrate are modified by the presence of the substances in the system.

Therefore, comfort indices related to water vapor permeability, air permeability, hygroscopicity, colour change and amount of dried emulsion on the substrate were evaluated [1]. 


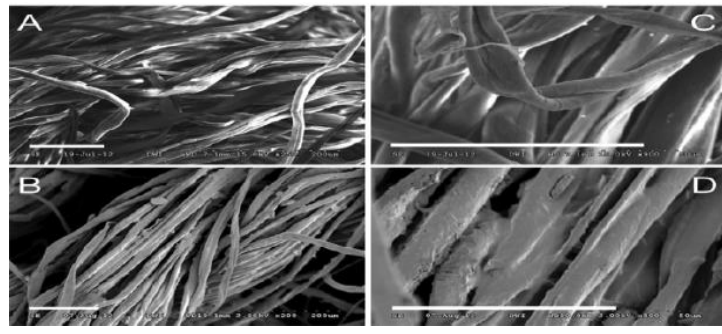

Figure 3. SEM aspect of treated (B, D) and untreated (A, B) cotton substrate

\subsection{Effect of Emulsion of an Antibacterial Activity on Treated Cotton Fabrics}

After the samples were dried, there was a significant loss of water through evaporation that increased with the concentration of chitosan carbohydrate polymer. When the concentrations of beeswax and Ethanol Extract Propolis (EEP) were increased while maintaining the concentration of chitosan constant, the emulsion retained by the textile substrate increased.

The presence of glycerol prevents the total drying of the polymer, maintaining its elastic state on the textile fibers, hence preserving the emulsion wet and the stickiness level is slowly increasing with humidity.

The Scanning Electronic Microscopy (SEM)pictures show that the emulsion is introduced in the fabric as a filmcovering the fibers/yarns and not the surface of the presence of glycerol prevents the total drying of the polymer, maintaining its elastic state on the textile fabric (figure 3. B \& D). The small formations visible at yarn level are beeswax particles. The higher concentration of beeswax has a negative effect on the emulsion as it tends to form these small particles that are not implanted in the chitosan polymer, leading to an unpleasant touch. The presence of propolis had changed the color of the impregnated knitted fabric into yellow-brown.

The evidence is that the intensity of the colour $(\mathrm{K} / \mathrm{S})$ for the witness sample is 0.12 , while for the treated samples the intensity varies with the concentration of propolis from $\mathrm{K} / \mathrm{S}=0.69$ for $25 \mathrm{ml} / \mathrm{l}$ to $\mathrm{K} / \mathrm{S}=2.11$ for $125 \mathrm{ml} / \mathrm{l}$. The higher concentration of propolis in relation to chitosan amplified their antibacterial effectiveness on gram positive bacteria while the cumulated action of Chitosan, Propolis and Beewax inhibited the entire Gram negative bacteria on the samples. Ethanol Extract of propolis (EEP) was the released agent with the help of chitosan polymer. Meanwhile, chitosan concentration is mainly responsible for the emulsion stabilization and for embedding EEP in the polymer. Hence, the emulsion might not be stable when the concentration of chitosan is low [1].

\subsection{Possible Mechanisms of Antimicrobial Finishes on the Fibres}

The antibacterial can be grouped into two based on the mode of attack on microorganisms. First group consist of chemical that operate by controlled-release mechanism. The antimicrobial is slowly released from a reservoir either on the fabric/yarn surface or in the core of the fibre. Such "leaching" type of antimicrobial can be extremely effective against microbes on the fibre surface or its surrounding environment.

The second group consists of molecules that are chemically bound to fibre surfaces.

These products can only control those microbes that are present on the fibre surface excluding the surrounding environment. These "Bound" types antimicrobials, due to their attachment on the fibre, can possibly be abraded or neutralize hence losing its long term durability [18].

\subsection{Durability Tests}

Tensile strength of the fabrics, Abrasion resistance, Stiffness, Moisture diffusion, heat transmission resistance, and air permeability are the main factors that can imitate the comfort ability of the fabric. For a textile to be considered comfortable, water vapor Permeability from the skin must occur in order to transport perspiration so that a wearer is no longer feeling discomfort [2].

Table 2. Antibacterial activity before and after padding methods [22]

\begin{tabular}{|c|c|c|c|c|c|c|c|c|}
\hline \multirow[t]{2}{*}{ Antimicrobial agent } & \multirow[t]{3}{*}{ Application method } & \multirow[t]{3}{*}{ bacteria } & \multicolumn{6}{|c|}{$\%$ Reduction in CFU of bacteria } \\
\hline & & & & & Laund & ry cycle & & \\
\hline & & & 0 & 1 & 2 & & 4 & 5 \\
\hline UN & - & E. coli & NR & NR & NR & NR & NR & $\mathrm{NR}$ \\
\hline UN & - & S. aureus & NR & NR & NR & NR & NR & NR \\
\hline \multirow[t]{4}{*}{ Triclosan $(60 \mathrm{~g} / \mathrm{L})$} & Pad-dry & E. coli & 100 & 100 & 100 & 100 & 99.99 & 99.98 \\
\hline & Pad dry cure & E. coli & 100 & 100 & 100 & 100 & 99.99 & 99.98 \\
\hline & Pad-dry & S. aureus & 100 & 100 & 100 & 100 & 99.99 & 99.98 \\
\hline & Pad dry cure & S. aureus & 100 & 100 & 100 & 100 & 99.99 & 99.98 \\
\hline \multirow[t]{4}{*}{ Silver $(10 \mathrm{~g} / \mathrm{L})$} & Pad-dry & E. coli & 92.5 & 92.3 & 91.84 & 91.67 & 91.34 & 91.13 \\
\hline & Pad dry cure & E. coli & 92.5 & 92.1 & 91.89 & 91.63 & 91.34 & 91.14 \\
\hline & Pad-dry & S. aureus & 95.65 & 95.39 & 95.21 & 94.92 & 94.73 & 94.48 \\
\hline & Pad dry cure & S. aureus & 95.67 & 95.34 & 95.2 & 94.95 & 94.71 & 94.44 \\
\hline \multirow[t]{3}{*}{ Chitosan $(5 \mathrm{gL})$} & Pad-dry & E. coli & 63.01 & 37.74 & 33.89 & 27.13 & 20.49 & 29.96 \\
\hline & $\begin{array}{l}\text { Pad dry cure } \\
\text { Pad-dry }\end{array}$ & $\begin{array}{l}\text { E. coli } \\
\text { S. aure }\end{array}$ & $\begin{array}{l}69.23 \\
72.24\end{array}$ & $\begin{array}{l}51.39 \\
4398\end{array}$ & $\begin{array}{l}47.92 \\
4067\end{array}$ & $\begin{array}{l}43.85 \\
34.81\end{array}$ & $\begin{array}{l}35.53 \\
28.94\end{array}$ & $\begin{array}{l}21.83 \\
21.83\end{array}$ \\
\hline & $\begin{array}{l}\text { Pad-dry } \\
\text { Pad dry cure }\end{array}$ & $\begin{array}{l}\text { S. aureus } \\
\text { S. aureus }\end{array}$ & $\begin{array}{l}7.24 \\
81.37\end{array}$ & $\begin{array}{l}4398 \\
68.38\end{array}$ & $\begin{array}{l}40.67 \\
64.59\end{array}$ & $\begin{array}{l}34.81 \\
57.6\end{array}$ & $\begin{array}{l}28.94 \\
52.07\end{array}$ & $\begin{array}{l}21.83 \\
48.97\end{array}$ \\
\hline
\end{tabular}

\subsection{Laundering Test for Antibacterial after Treatment}

Laundering durability test was carried out as per AATCC Test method 143-96.

A MAYTAG Model A806 washer and dryer were used for Laundering purposes. The laundering process was repeated five times for each treatment (table 2). All solutions were incubated for 48 hours at $37{ }^{\circ} \mathrm{C} \pm 2{ }^{\circ} \mathrm{C}$ followed by a count of the colonies that formed on the dish. The values were recorded and averaged by the following formula [22]: 


$$
\text { Log Reduction }\left(\frac{\mathrm{CFU}}{\mathrm{ml}}\right)=\left(\frac{\mathrm{A}}{\mathrm{B}}\right)
$$

$\mathbf{C F U}=$ colony forming units

$\mathbf{A}=$ number of bacteria recovered from treated fabric after 24 hours

$\mathbf{B}=$ number of bacteria recovered from treated fabric at zero contact time.

$\mathrm{ml}=$ volume of the sample

\subsection{The Possible Negative Side Effects of Antibacterial Clothing on the Human Skin}

Up to date none of the natural compounds have been reported to have negative side effects on the human skin when used as antibacterial clothing, but some antibacterial have fewer problems in skin irritation and discomfort. However, some antibacterial have been associated with a range of adverse effects range from mild to very serious depending on the antibiotics used and the individual's allergic. Fabrics treated with antibacterial chemicals such as Silver in ionic form, triclosan and trichlorcarban are leaching the toxic substances into the environment every time they are washed [23]

\subsection{Some Factors Likely Affecting Efficacy of Antibacterial}

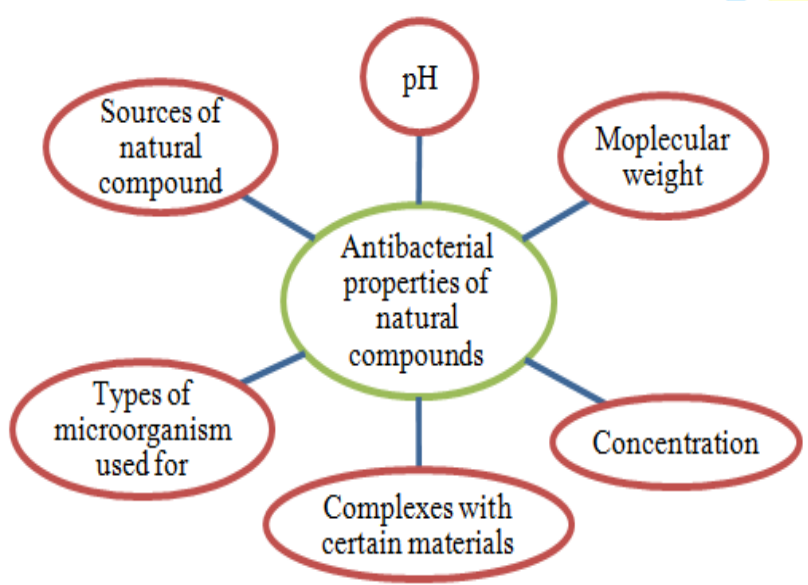

Figure 4.different factors affecting antibacterial properties

$$
\text { [24] }
$$

\section{Conclusion}

Based on the evidences collected, The antibacterial agent of natural products (Chitosan, Beewax and propolis) has show its effectiveness in inhibiting bacteria both gram positive and gram negative despite the fact that propolis was the releasing agent from the emulsions. The presence of the biologically active natural compounds on the cotton substrates modified the surface of the textile fibers. The treatment also improved fabric comfort properties, the cotton substrates became less air permissive and more hygroscopic after the treatment. The used of microcapsules of honey as core and chitosan as a shield on the medical gauzes showed good performance in the wound healing and that was the proved for the usage of honey and Chitosan as an antibacterial in treating medical gauzes for the human diabetes. Therefore, antibacterial performance of the functionalized cotton fabrics treated with those biologically active natural compounds has the potentials to be used in medical fields. Up to date none of the natural compounds have been reported to have negative side effects on the human skin when used as antibacterial clothing. The reviewed paper recommended the need to carry out further studies on the antimicrobial activity of bee products alone (beeswax and propolis).

\section{Acknowledgements}

The reviewer would like to offer his sincere thanks and appreciation to the board members from Department of Chemistry, Arba Minch University, Arba MinchEthiopia for the support provided.

\section{References}

[1] Danko A. et al. (2013) "Antibacterial Finishing of Cotton Fabrics Using Biologically Active natural Compounds", Fibers and Polymers, 14 (11) pp. 1826-1833.

[2] Khaled E. El-Nagar (2012) "Medical Dressing Treated with Honey /Chitosan Microencapsules", nternational Journal of Chemistry, 4 (2).

[3] Zanoaga M. and Tanasa F. (2014) "Antimicrobial reagents as functional finishing for textiles intended for biomedical applications. I. Synthetic organic compounds", Chem. J. Mold., (9) pp. 14-32.

[4] Greenaway W., et al. (1987) "The analysis of bud exudates of populusX euramericina and of propolis, by Gas Chromatography- Mass Spectrometry". Proc. Royal ociety. London, (232), pp. 249-272.

[5] Purwar, R., and Joshi, M., (2004) "Recent Developments in Antimicrobial Finishing of Textiles, Review", AATCCR, 4, p. 22.

[6] Daugsch A., et al. (2008) "Brazilian red propolis - chemical composition and botanical origin", Evidence-Based Complementary and Alternative Medicine, 5 (4), pp. 435-441. 
[7] Castaldo S. and Capasso F., (2002)"Propolis, an old remedy used in modern medicine," Fitoterapia, 73 (1), pp. S1-S6.

[8] Marcucci MC., et al. (2001) "Phenolic compounds from Brazalianpro"polis with Pharmacological activities", J. Ethnopharmacol. 74 pp.105-112.

[9] Gao R. (2009) "Use of Chitosan in Surface Modification of Textile Materials", Roumanian Biotechnological Letters, 13 (6), pp. 4037-4048.

[10] Bogdanov S. (2004) "Beeswax: quality issues today", Bee World, (85) pp. 46-50.

[11] Kurstjens SP. et al.(1991) "Synthesis and secretion of beeswax in honeybees", Apidologie (22), pp. 21-36.

[12] Lang G. and Clausen T., (1989) "Chitosan: The commercial uses and application in: cosmetics, Chitin and Chitosan Sources, Chemistry, Biochemistry, Physical Properties and Applications", Elsevier Applied Science, London and New York, pp. 139-147.

[13] Web: www.elsevier.com/locate/cropro.

[14] Gao Y. and Cranston R. (2008) "Recent Advances in Antimicrobial Treatments of Textiles", Textile Research Journal, 78 (1) pp. 60-72.

[15] NallahalliShivarajegowdaSurendra, et al. (2012)"Antimicrobial Activity of Propolis of Trigona sp. and Apismellifera of Karnataka, India", Prime Journal of Microbiology Research (PJMR), 2(2), pp. 80-85.

[16] Bogdanov S. (2009) Beeswax: production, properties composition and control. Beeswax book, Bee Product Science, Switzerland.

[17] Purwar, R., and Joshi, M., (2004) "RecentDevelopments in Antimicrobial Finishing of Textiles a Review, ATCC Review, 4, pp. 22-26.

[18] Von Moody and Howard L. Needles (2004) TUFTED CARPET: Textile Fibers, Dyes, Finishes, and Processes p.149.

[19] Sheila Shahidi and Jakub Wiener (2009) "Antibacterial Agents in Textile Industry" Department of Textile, Faculty of Engineering,Islamic Azad University, Arak Branch, Arak.

[20] 20. Hossein H. and Sina M., (2013) "Durable antibacterial finish on cotton fabric using hydrogel-silver Nanocomposite", Chemistry Department, Payame Noor University, Tehran, Iran, pp.19395- 4697.

[21] Sadeghi, M. and Ghasemi, N. (2012), "Synthesis and study on effect of various chemical conditions on the swelling property of collagen-g-poly (AA-co-IA) superabsorbent hydrogen", Ind. J. Sci.Tech. (5) pp. 1879-1884.

[22] GuneetDhimanand .Chakraborty J. (2015), "Antimicrobial performance of cotton finished with triclosan, silver and chitosan", National Institute of Technology, Jalandhar 144011, India.

[23] Dirk Hoefer and Timo R. Hammer (2011) "Antimicrobial Active Clothes Display No Adverse Effects on the Ecological Balance of the Healthy Human Skin Microflora", Institute for Hygiene and Biotechnology, Hohenstein Institutes, SchlossHohenstein, Boennigheim, Germany, 2011 (369603)

[24] Mahmoud Hosseinnejada and Seid Mahdi Jafari. (2016) "Evaluation of Different Factors AffectingAntimicrobial Properties of Chitosan, Review", International Journal of Biological Macromolecules, (85) pp.467475 . 